\title{
Modern obstetrics and the general practitioner
}

\author{
E WILKES, R A DIXON, J KNOWELDEN
}

British Medical fournal, 1975, 4, 687-690

In a changing obstetric world we thought it timely to survey the work and attitudes of general practitioners with special obstetric training. Such a survey might have useful service and educational implications. We decided therefore to send a questionnaire to holders of the DObstRCOG qualification old enough to have settled into their practices but not so senior that they had begun to restrict their obstetric responsibilities. We were interested also to obtain some secondary information on gynaecology, family planning, and abortion from the viewpoint of the general-practitioner obstetrician.

\section{Methods}

The survey was based on a long questionnaire containing 52 questions. This was sent to holders of the DObstRCOG who had obtained that qualification in 1963,1967, or 1971 and who were still on the Medical Register. Since we thought that rural practitioners might have a disproportionately large obstetric work load holders of the DObstRCOG with a rural address who obtained the qualification in $1964,1965,1966,1968,1969$, or 1970 were also circularised with the questionnaire and the findings were analysed separately. In only a few instances were minor differences noted in the findings of the two surveys.

\section{Findings of main survey}

The holders of the DObstRCOG from the three main survey years totalled $1809 ; 26 \%$ were not on the Medical Register, and the remain-

\footnotetext{
Department of Community Medicine, Sheffield University, Sheffield S10 2RX

R A DIXON, BSC, PHD, lecturer

J KNOWELDEN, MD, FRCP, professor of community medicine

E WILKES, FRCP, FRCGP, professor of community care and general practice
}

ing $1335(74 \%)$ were circularised. A total of 634 replied that they were in general practice in the United Kingdom. These formed $100 \%$ of the main survey but in such a questionnaire not all the questions were always answered so replies often did not add up to the full $100 \%$. Details of the 1335 circularised are given in table $\mathbf{I}$.

The 634 responders included 33 single-handed practitioners and 19 who worked in groups of eight or more doctors, but most were in three- or four-doctor partnerships, the mean partnership size being 4.3. Thirty-five per cent categorised their practices as urban, $18 \%$ as rural, and $46 \%$ as mixed. Most $(98 \%)$ of the respondents were graduates from British or Irish medical schools. The commonest additional postgraduate qualifications were MRCGP $(14 \%), \mathrm{DCH}$ $(11 \%)$, and DA $(7 \%)$.

TABLE I-Response to main survey of doctors who obtained DObstRCOG in 1963,1967 , or 1971

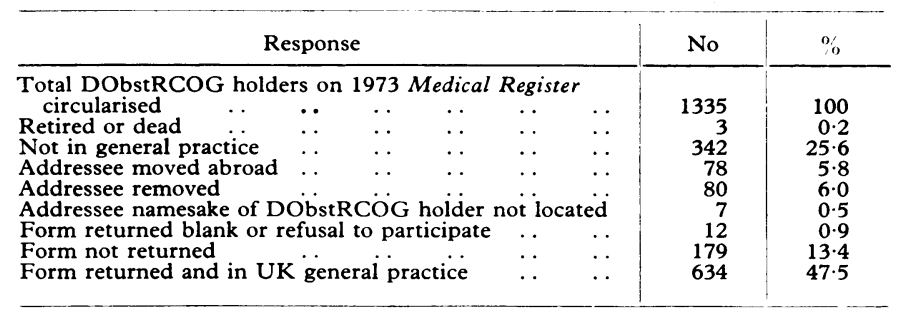

The mean age of the sample was 36 years; $82 \%$ were men, $11 \%$ women, and $7 \%$ of unknown sex. Generally the respondents had usually registered the year before passing the DObstRCOG examination and entered general practice within 12 months of obtaining it.

Obstetric training and responsibilities-The main reasons given for taking the DObstRCOG examination were: because an obstetrics post had recently been completed $(42 \%)$, because of a special interest in obstetrics $(35 \%)$, to equip themselves for general practice $(12 \%)$, to be included in the obstetric list $(3 \%)$, and because of mixed or other reasons $(8 \%)$.

Relevance of training and recent trends-Only 3\% of doctors found their obstetric training mainly irrelevant now, and $60 \%$ found it as useful and relevant as ever. The remaining $37 \%$ found the training 
still useful though less relevant in contemporary practice. Altogether $35 \%$ of the doctors had found little change recently in their obstetric responsibilities, and another $35 \%$ had experienced a gradual decline. Only $10 \%$ reported a rapid decrease and nearly twice as many $(18 \%)$ reported an actual increase in their obstetric work load. Although $58 \%$ of these doctors gave total care in normal obstetric cases, no less than $37^{\circ} \%$ referred most normal cases to a consultant unit.

Obstetric work load-Most $\left(84_{\%}^{\circ}\right)$ of the doctors held special antenatal clinics. A district midwife was attached to $76 \%$ of the practices, and she attended the practice antenatal clinics for $69 \%$ of the doctors. Instruction about labour was given by the midwife for $81 \%$ of the doctors, by the doctor himself in $35 \%$ of cases, and by a physiotherapist in $25 \%$. Thus nearly two-thirds of practitioners gave no such instruction personally, and for $8 \%$ of these doctors apparently no one else did. In $65 \%$ of practices the patients inspected the labour unit in which they were to be delivered as part of their routine antenatal preparation. The doctors estimated that they had been responsible for a mean of 31 confinements in the past 12 months and had attended nearly half of these personally (table II). Eighteen per cent were responsible for occasional deliveries ( $0-4$ yearly) but $28 \%$ were responsible for 40 deliveries or more a year (table III). The mean number of confinements personally attended each year ranged from three, when there was no general-practitioner obstetric unit readily available, to 19 , when the unit was two miles from the practice or closer. When asked to estimate the yearly average number of low forceps applications made by them in the last few years in general practice $58 \%$ said they had not performed any forceps deliveries and another $27 \%$ said they had performed three or fewer a year (table IV). Fifty-six per cent accepted, but $44 \%$ refused, responsibility for occasional domiciliary confinements (two or three each year).

TABLE II-Number of yearly confinements and forceps deliveries according to distance from general-practitioner obstetric unit

\begin{tabular}{|c|c|c|c|c|}
\hline \multirow[b]{2}{*}{$\begin{array}{l}\text { Distance from } \\
\text { practice to } \\
\text { GP obstetric } \\
\text { unit } \\
\text { (miles) }\end{array}$} & \multirow{2}{*}{$\begin{array}{c}\text { No }(\%) \text { of } \\
\text { practitioners }\end{array}$} & \multicolumn{3}{|c|}{ Estimated yearly confinements } \\
\hline & & $\begin{array}{l}\text { Mean No for } \\
\text { which } \\
\text { responsible }\end{array}$ & $\begin{array}{l}\text { Mean No ( }(" \%) \\
\text { personally } \\
\text { attended }\end{array}$ & $\begin{array}{l}\text { Mean No ( }\left(_{\sigma}^{\circ}\right) \text { of } \\
\text { low forceps } \\
\text { applications } \\
\text { yearly }\end{array}$ \\
\hline $\begin{array}{c}\quad<3 \\
\quad 3-5 \\
\geqslant 6 \\
\text { No unit } \\
\text { Not known }\end{array}$ & $\begin{array}{l}212(33) \\
112(18) \\
150(24) \\
155(24) \\
5(1)\end{array}$ & $\begin{array}{l}38 \cdot 1 \\
36 \cdot 3 \\
27 \cdot 4 \\
19 \cdot 7\end{array}$ & $\begin{array}{r}19 \cdot 4(51) \\
14 \cdot 2(39) \\
12 \cdot 5(46) \\
3 \cdot 1(16)\end{array}$ & $\begin{array}{l}2 \cdot 6(7) \\
1 \cdot 6(4) \\
1 \cdot 1(4) \\
0 \cdot 2(1)\end{array}$ \\
\hline Total & $634(100)$ & $30 \cdot 5$ & $12.9(42)$ & $1.5(5)$ \\
\hline
\end{tabular}

TABLE III-Percentages of doctors responsible for different numbers of deliveries a year

\begin{tabular}{l|r|r|r|r|r|r|r|r}
\hline $\begin{array}{l}\text { No of deliveries a year } \\
\% \text { of doctors }\end{array}$ & $0-4$ & -9 & -19 & -29 & -39 & $\geqslant 40$ & $\begin{array}{c}\text { Not } \\
\text { known }\end{array}$ & Total \\
7 & 18 & 5 & 15 & 16 & 12 & 28 & 7 & 100 \\
\hline
\end{tabular}

TABLE IV-Number of low forceps deliveries estimated per year

\begin{tabular}{c|c|c}
\hline $\begin{array}{c}\text { No of yearly low forceps } \\
\text { deliveries }\end{array}$ & $\begin{array}{c}\text { Performed by main } \\
\text { survey doctors } \\
\text { (\% of 634 doctors })\end{array}$ & $\begin{array}{c}\text { Performed by rural } \\
\text { survey doctors } \\
\text { (\% of 242 doctors })\end{array}$ \\
\hline 0 & 58 & 48 \\
$1-3$ & 27 & 36 \\
$4-8$ & 10 & 12 \\
Not known & 3 & 3 \\
\hline
\end{tabular}

General-practitioner obstetric units-The practices of a third of the doctors were less than three miles from a general-practitioner obstetric unit (table II), and this proximity seemed to be associated with responsibility for more confinements, a slightly increased proportion personally attended, and rather more low forceps deliveries being undertaken. For $24 \%$ there was no general-practitioner obstetric unit available at all. The general-practitioner obstetric units were separate and distant from the consultant unit for $39 \%$ of doctors and integrated with, or only a few yards from, the unit for $34 \%$. The remainder had no general-practitioner unit available. The general practitioner-consultant relationships were described as friendly in $76 \%$ of replies, indifferent in $13 \%$, hostile in $2 \%$, and uncertain in $9 \%$.

Special skills-Nearly all the practitioners $(92 \%)$ were experienced in pudendal block, $16 \%$ in general anaesthesia, and $4 \%$ in spinal and
$5 \%$ in epidural techniques. For $32 \%$ of doctors an experienced anaesthetist colleague was usually available. Altogether $45^{\circ} \%$ of the practitioners were familiar with modern obstetric monitoring equipment. Seven per cent held a clinical assistant post that required attendance at antenatal clinics, and $6 \%$ held a post in which they were on obstetric call at night, and $3^{\circ}{ }_{0}$ had a post demanding both these duties. If offered an obstetrics clinical assistant post involving both these responsibilities $37^{\circ}$, would accept it, $40^{\circ}{ }_{n}$ would have to refuse as they were too busy, $6 \%$ were too distant, and $5 \%$ felt that they now lacked confidence. In $8 \%$ the reasons were not specified and $3 \%$ already held such a post.

Clinical practice-Antenatal supervision was given at least monthly in the first trimester of pregnancy by $83^{\circ}{ }_{0}$ of practitioners, at least monthly or fortnightly in the second trimester by $97^{\circ}$, and at least fortnightly or weekly in the last trimester by $95^{\circ}{ }_{0}$. Forty-two per cent of the doctors said they usually examined their patients vaginally on booking and also whenever indicated. Only a small proportion (4\%) examined their patients vaginally only on booking, and $50 \%$ only when there was a clinical indication. Seventy-six per cent of the doctors obtained haemoglobin estimations on booking and whenever indicated, $8 \%$ only on booking, and $13 \%$ only when there was a clinical indication.

Antenatal care-We attempted to grade the quality of antenatal care by analysing the number of observations said to be included in the routine antenatal session. We especially noted any mention of weight and blood pressure measurements and urine analysis and any mention of the following: fundal height; fetal heart; presentation; haemoglobin estimation; urine culture; vaginal examination; cervical smear; varicose veins; and folic acid prescribing. On an arbitrary but objective scale we used these measurements and examinations to assess the general standard of antenatal care (table V).

TABLE V-Standards of antenatal and postnatal care given by different proportions of doctors

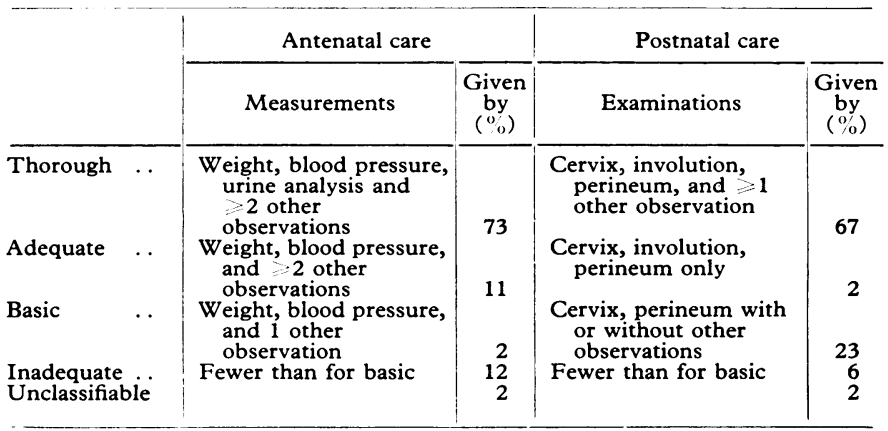

Postnatal examination-The standard of the postnatal examination was similarly classified. Special note was made of $(a)$ an assessment of involution with pelvic, vaginal, or abdominal examination; (b) the examination of the cervix or the taking of a smear or examination by speculum; $(c)$ the healing of the perineum. We also noted whether blood pressure was measured, urine analysed, or advice given on obesity or contraception. Arbitrarily, and similarly, a thorough postnatal examination was defined as including an assessment of the cervix, the degree of involution, the perineal repair, and one or more other observations. The results are given in table V.

Further clinical obstetric practice-With the trend towards more active obstetrics about a third of deliveries are now induced. ${ }^{1}$ When the practitioners thought induction was indicated over half $(53 \%)$ did not do this themselves. When attempted by the practitioner surgical rupture of the forewaters was easily the commonest method, and was used by $33 \%$ of them. Medical induction (castor oil or enema) was used in only $3 \%$, hormonal induction in $1 \%$, and a combination of surgical and hormonal induction in $7 \%$ of cases. Three per cent of doctors gave no answers or unclassifiable ones. The doctors were then asked how they would deal with certain obstetric problems. The problems and the doctors' responses are shown in table VI.

Gynaecological practice-Nearly all the practitioners $(90 \%)$ said that they routinely dealt with many gynaecological problems in their practice, attempted the treatment of menstrual disorders $(98 \%)$, and gave advice to infertile couples $(96 \%)$. When asked to describe postgraduate experience in medical gynaecology as vital, useful, or unimportant, $48 \%$ replied that they thought it was vital, $50 \%$ that it was useful, and $1 \%$ that it was unimportant. Sixty per cent wanted more training in venereology. 
TABLE VI-Doctors' responses to one question on questionnaire

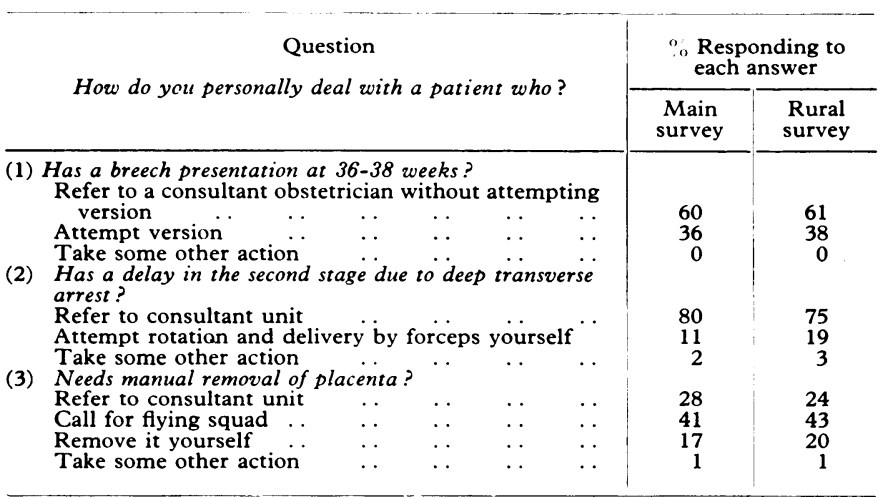

Contraception-Nearly all $(92 \%)$ the doctors offered family planning advice whenever they thought it was appropriate. Five per cent would proffer such advice only when the patient requested it. Only two doctors $(0.3 \%)$ said they would proffer advice only on request to married women or would never offer such advice at all. Twenty-four per cent of doctors had received a Family Planning Association (FPA) training, and $34^{\circ}$ inserted intrauterine devices. Among contraindications to the use of the oral contraceptive $88^{\circ}$ of doctors mentioned a previous history of thrombophlebitis, $67^{\circ}{ }_{0}$ included liver disease, $60^{\circ}$ o included hypertension, and anxiety or depression was considered a contraindication by $15 \%$ of the doctors. Less common difficulties, such as problems with contact lenses in patients taking oral contraceptives, were also mentioned by the doctors.

Abortion-On average six abortions were recommended per doctor in the 12 months before this survey but this figure excluded the five doctors (just under $1 \%$ ) who had recommended 50 or more. Seventyseven doctors $\left(12^{\circ}{ }_{0}\right)$ had recommended none and $141\left(22^{\circ}{ }_{\circ}^{\circ}\right)$ had recommended 10 or more (table VII). Most doctors $\left(60^{\circ}{ }_{0}\right)$ thought that the present Abortion Act was a reasonable compromise, $22^{\circ}$ thought it a major social advance, and $14^{\circ}{ }^{\circ}$ thought it a tragic mistake. Three per cent had other miscellaneous views.

Health education-In an attempt to estimate the degree of their concern for preventive health education the doctors were asked what they told mothers about the dangers of smoking in pregnancy. Twenty-five per cent said they did not routinely explain these dangers, $67^{\circ}{ }_{0}$ mentioned the lower birth weight, and only $8^{\circ}$, mentioned the possible danger of a stillbirth.

TABLE VII-Abortions recommended over past year

\begin{tabular}{ll|c|c|c|c|c|c|c|c}
\hline $\begin{array}{l}\text { No of abortions } \\
\begin{array}{c}\text { Recommended by } \\
\text { (") of doctors) }\end{array}\end{array}$ & $\ldots$ & 12 & 36 & 29 & 17 & 4 & 1 & 1 & 1
\end{tabular}

\section{Rural practitioner survey}

In $1964,1965,1966,1968,1969$, and 1970 a total of 3376 doctors obtained the DObstRCOG qualification. Questionnaires were sent to $274\left(8^{\circ}\right)$ of these doctors with an apparently rural or small town address in the Medical Register (30-60 from each year). Of those circularised 242 doctors $\left(88^{\circ}\right.$ ) responded and were in general practice in the United Kingdom. The sample included no medical graduates from overseas. Only three were women-that is, only $1 \%$ compared with $11^{\circ}$ in the main survey. The mean age was 36 years.

Only three doctors worked single-handed, only six worked in a group of eight or more doctors, and the mean number in the partnership for the rural survey was $4 \cdot 5$. Their commonest additional postgraduate qualifications were MRCGP $(16 \%), \mathrm{DCH}(10 \%)$, and DA $(7 \%)$. These were almost identical with the findings in the main survey sample.

Although the main survey did not exclude rural practitioners it was interesting to compare the two surveys (table VIII). A higher proportion of the rural doctors did low forceps deliveries and a higher proportion induced labour. They were more likely to attempt rotation of deep transverse arrest (see table VI). Although the general-practitioner obstetric unit was more often separate and distant from the consultant unit relationships between practitioners and consultants were more often friendly. Fewer rural doctors thought themselves in need of additional training in venereology. Perhaps the most striking feature of the comparison between the two surveys was that the rural practitioners were not exceptional in their obstetric experience and in most aspects were similar ro the main group of respondents.

TABLE VIII-Some comparisons between the main and rural surveys of general practitioners with DObstRCOG qualification

Summary of replies

\section{Discussion}

The training and standards of the general practitioner have clearly improved greatly over the past 10 or 15 years. ${ }^{2}$ Both the frequency and the quality of supervision shown by most of these practitioners seem, within the inevitable limits of any survey based on a self-administered questionnaire, to be highly satisfactory, and their clinical decision-making seems in line with good current practice.

There are, of course, some questions to be asked. Is it sensible that when about a third of these practitioners have obstetrics as a special interest only $3 \%$ hold operational clinical assistant posts in the specialty? Only $9 \%$ or $10 \%$ thought that their obstetric responsibilities were diminishing rapidly, and only $4 \%$ or $5 \%$ felt that they now lacked confidence and would refuse a clinical assistant post if offered. On the other hand, over a third did not hold but would accept such a post and $40-45 \%$ of each survey had experience of modern monitoring equipment.

There is some justification for the lack of confidence expressed by the small minority. Roughly half of the doctors did not induce labour and had either no general-practitioner obstetric unit or a separate unit more than five miles away. About half again had not been responsible for any forceps deliveries in recent years. More attention might possibly have been paid to antenatal haemoglobin estimations or vaginal examinations, but this shortcoming is surely an inevitable consequence of skilled doctors now referring about a third of their normal obstetric cases to a consultant unit. This implies a massive waste of skill in doctors who still mostly thought that their obstetric training was as relevant as ever. 
Yet, in the light of modern practice, the training itself could have been improved. In each survey over $90^{\circ}{ }_{0}$ offered family planning advice, but less than a quarter had received an FPA training and over half felt that they needed more training in venereology. Between a fifth and a quarter of these doctors apparently did not mention the dangers of smoking to pregnant mothers and the educational component of antenatal care seems largely to be dealt with by the midwife. This may well be a suitable delegation since so many of the doctors are men and some at least of the midwives are also trained to give contraceptive advice. The variable nature of the replies about the postnatal examination raises the possibility that the modern aims of this examination now need clarification.

The domiciliary confinements persist, despite theoretical banishment, and remind us that what is true in Knightsbridge may well be false in rural Lincolnshire. We must give understanding and support to those doctors who, for all that they may not relish it, do not feel able to refuse to attend at a home confinement. The survival of this phenomenon may be partly stubborn maternal self-indulgence but surely also represents our failure to provide inviting and reassuring hospital-based units.

It is a sign of the capacity of the conservative medical profession to adjust to social pressures-perhaps helped by the fact that $8.6 \%$ of births are now illegitimate ${ }^{1}$-that four out of five of these doctors felt that the present Abortion Act was either a reasonable compromise or a social advance.

\section{POSSIBLE MANAGERIAL IMPLICATIONS}

The consultant obstetrician clearly remains the central resource for the diagnosis and management of major obstetric abnormalities. The diminished birth rate may even permit a rare chance to improve standards.

A large minority of practitioners with special interest and experience need only an invitation to concern themselves more as clinical assistants in the increasingly complex technology of the consultant units. Some of these practitioners could perform duties at the level of responsibility of a registrar and could also act as liaison officers with most other practitioner colleagues who are unable to compete with their level of practice and skill. We may have to accept that many of these other practitioners, interested and well-trained though they may be, cannot easily be involved in this ever more hospital-based obstetric specialisation. They are often themselves hedged in by high consultation rates and a crowded appointments system. Only the enthusiast can make time for his obstetric duties; our survey showed that only half the confinements were attended by the doctor. Another survey $^{3}$ showed that only a third of confinements in an urban general-practitioner obstetrics unit were attended personally by the responsible practitioner. This is especially likely when a patient seems to need the attention of only a midwife, perhaps largely because of the doctor's own efficient antenatal supervision.

Hence probably mothers will tend to receive ever more highquality impersonal care, with complex skills immediately available in case of need, but in a confinement lacking the company, reassurance, and continuity of a great family occasion. This is a managerial problem that we have not yet solved. It may be eased by offering more open access for district midwives and practitioners to consultant units, with patients discharged back to home care six, 12, or 24 hours after a normal delivery. For many doctors, however, it seems that their contribution should be restricted to an antenatal and postnatal role, and here too there is scope for improvement.

The routine of antenatal care seems still to be based on the management of toxaemia and the dangers of the contracted pelvis. These cannot of course be neglected, but surely they need supplementing when parents are younger, more unsupported, and less educated in family responsibilities than ever before. The average girl may be uniquely receptive in her antenatal period to family-orientated training. She needs, from prac- titioner and midwife, health visitor and physiotherapist, information about the emotional as well as the physical needs of her baby. She needs to hear about the importance of affection, stimulation, and play for the baby and about the prevention of infant obesity or dental caries, and she needs to gain understanding and tolerance of minor but common behaviour problems. In these circumstances relaxation exercises and blood pressure measurements are not enough.

The old obstetrics diploma therefore needs to be replaced by a diploma that will still include elements of the old operative obstetrics, but will have added more training in gynaecology, venereology, the preparation of mothers for parenthood, elementary genetic counselling (more important than ever with the prenatal diagnosis of fetal abnormalities), and developmental paediatrics. Doctors also need more training in an understanding of the mechanisms of population control, including sociological and psychological factors as well as contraceptive technology. Some of these educationl changes are already in hand with the new DRCOG examination and will provide a valuable and genuine role for the interested practitioner in up-grading obstetric and parental care even while his forceps gather dust. Close co-operation with well-trained midwives and health visitors at the antenatal clinics is essential, since ideally it is here that potential marital stresses or battered babies can be identified and helped.

It seems that any further wide-ranging developments in general practice obstetrics would run counter to recent trends in medical care and so are unlikely. Indeed, general-practitioner maternity units with an unacceptably low bed-occupancy rate will have to be closed. This should not be done lightly, however. Many of these units would lend themselves quite easily to a changed role as community hospitals with geriatric and day care facilities, while retaining a few obstetric beds for suitable patients needing, for example, bed rest before delivery or longer than average convalescence after it. The very slow decline in the practitioners' obstetric involvement gives some indication of the high quality of the care provided and confirms the continuing need for general instruction in obstetrics for undergraduates.

We thank the many general practitioners who submitted themselves so patiently to the scrutiny of a long questionnaire, the Royal College of Obstetricians and Gynaecologists for making available their lists of diplomates, and our colleagues in the department of community medicine for their advice and help, especially Mrs M Nicholson, who distributed, coded, and analysed the questionnaires, and Mrs S Harris for secretarial help.

\section{References}

${ }^{1}$ Department of Health and Social Security, On the State of the Public Health, Annual Report of the Chief Medical Officer for 1973. London, HMSO, 1974.

2 Butler, N R, and Donham, D G, Perinatal Mortality. Edinburgh, Livingstone, 1963.

${ }^{3}$ Porteous, M R, 1974, personal communication.

Are strokes common after removal of cataract? If so, is it advisable to give anticoagulants postoperatively?

Strokes are rare postoperatively in patients who have had cataract extraction and probably no more frequent than is to be expected as a chance occurrence in old people. The operation is performed with the patient supine and in Britain usually under a general anaesthetic. It seems unlikely that cerebral blood flow is impaired during the procedure. Patients are now usually got up on the first postoperative day, so that the risk of thrombosis in any part of the body has been reduced. 